\title{
Reconciled climate response estimates from climate models and the energy budget of Earth
}

Article

Accepted Version

Richardson, M., Cowtan, K., Hawkins, E. and Stolpe, M. B. (2016) Reconciled climate response estimates from climate models and the energy budget of Earth. Nature Climate Change, 6 (10). pp. 931-935. ISSN 1758-678X doi: https://doi.org/10.1038/nclimate3066 Available at https://centaur.reading.ac.uk/65992/

It is advisable to refer to the publisher's version if you intend to cite from the work. See Guidance on citing.

To link to this article DOI: http://dx.doi.org/10.1038/nclimate3066

Publisher: Nature Publishing Group

Publisher statement: See Related URLs for a free link to the published version of record.

All outputs in CentAUR are protected by Intellectual Property Rights law, including copyright law. Copyright and IPR is retained by the creators or other copyright holders. Terms and conditions for use of this material are defined in the End User Agreement.

www.reading.ac.uk/centaur 


\section{CentAUR}

Central Archive at the University of Reading

Reading's research outputs online 
(c) 2015. All rights reserved.

\section{Reconciled climate response estimates from climate models and the energy budget of Earth}

Mark Richardson*

Jet Propulsion Laboratory, California Institute of Technology, Pasadena, U.S.A.

Email: markr@jpl.nasa.gov Phone: (+1) 818-354-4270

Address: Jet Propulsion Laboratory, M/S 233-300, 4800 Oak Grove Drive, Pasadena, CA 91101, U.S.A.

Kevin Cowtan

Department of Chemistry, University of York, York, UK

Ed Hawkins

National Centre for Atmospheric Science, Department of Meteorology, University of Reading,

Reading, UK

Martin B. Stolpe

Institute for Atmospheric and Climate Science, ETH Zurich, Zurich, Switzerland

(C) 2015. All rights reserved. 
(C) 2015. All rights reserved.

Climate risks increase with mean global temperature ${ }^{1}$ so knowledge about the amount of future global warming should better-inform risk assessments for policymakers. Expected near-term warming is encapsulated by the Transient Climate Response (TCR), formally defined as the warming following 70 years of $1 \%$ per year increases in atmospheric $\mathrm{CO}_{2}$ concentration, by which point atmospheric $\mathrm{CO}_{2}$ has doubled. Studies based on Earth's historical energy budget have typically estimated lower values of TCR than climate models, suggesting that some models could overestimate future warming. ${ }^{2}$ However, energy-budget estimates rely on historical temperature records that are geographically incomplete and blend air temperatures over land and sea ice with water temperatures over open oceans. We show that there is no evidence that climate models overestimate TCR when their output is processed in the same way as the HadCRUT4 observation-based temperature record. ${ }^{3,4}$ Models suggest that air-temperature warming is $24 \%$ greater than observed by HadCRUT4 over 1861-2009 because slower-warming regions are preferentially sampled and water warms less than air. ${ }^{5}$ Correcting for these biases and accounting for wider uncertainties in radiative forcing based on recent evidence, we infer an observation-based best estimate for TCR of $1.66{ }^{\circ} \mathrm{C}$ with a $5-95$ $\%$ range of $1.0-3.3^{\circ} \mathrm{C}$, consistent with the climate models considered in the IPCC $5^{\text {th }}$ Assessment Report.

TCR for the Climate Model Intercomparison Project, phase 5 (CMIP5) models is defined using simulations in which atmospheric $\mathrm{CO}_{2}$ increases at $1 \%$ per year and the multi-model mean is $1.8^{\circ} \mathrm{C}$ (1.2-2.4 ${ }^{\circ} \mathrm{C}$, henceforth bracketed values refer to $5-95 \%$ ranges).$^{6-8} \mathrm{TCR}$ has also been estimated from Earth's energy budget using:

$$
T C R=\frac{\Delta T}{\Delta F} \Delta F_{2 \times C O_{2}}
$$


(c) 2015. All rights reserved.

Where $\Delta T$ is observed change in temperature, $\Delta F$ is change in radiative forcing and

$\Delta \mathrm{F}_{2 \times \mathrm{CO}_{2}}$ is the forcing change for doubled atmospheric $\mathrm{CO}_{2}$. Energy-budget calculations have recently been able to provide more constrained estimates of TCR due to increased amplitudes of

$\Delta T$ and $\Delta F \quad$ relative to their uncertainties (see Supplementary Information). These energy-budget estimates have typically fallen below the CMIP5 multi-model mean, e.g. $1.5^{\circ} \mathrm{C}$ from Bengtsson \& Schwartz $\left(1.0-1.9^{\circ} \mathrm{C}\right)^{9}, 1.3^{\circ} \mathrm{C}\left(0.9-2.0^{\circ} \mathrm{C}\right)$ from Otto et al. $(2013)^{2}$ and $1.3^{\circ} \mathrm{C}(0.9-2.5$ $\left.{ }^{\circ} \mathrm{C}\right)$ from Lewis \& Curry $(2015)^{10}$.

The lower best estimates of TCR from these observation-based studies relative to CMIP5 may be due to a combination of: biases in observed temperature series, ${ }^{11}$ varying efficacy of different forcings, ${ }^{12-16}$ time- and history-dependence of $\mathrm{TCR}^{17}{ }^{17}$ internal variability, ${ }^{18}$ overestimate of forcings, ${ }^{19}$ efficacy of ocean heat uptake, ${ }^{20-22}$ structural uncertainties in energy-budget calculations or lower real-world TCR.

We focus on potential biases in temperature series due to geographical incompleteness of the data ('masking') and the combination of air and water measurements ('blending') by applying energy-budget TCR calculations to CMIP5 simulations and observations. We calculate energy-budget TCR with the Otto et al. (2013) method, henceforth 'Otto', which uses differences between an early baseline period and a recent reference period:

$$
T C R=\frac{T_{2000-2009}^{\prime}-T_{1861-1880}^{\prime}}{F_{2000-2009}^{\prime}-F_{1861-1880}^{\prime}} \Delta F_{2 \times \mathrm{CO}_{2}}
$$

Where $T_{2000-2009}^{\prime}$ is the mean temperature anomaly over 2000-2009, and the other symbols follow this format. We shift the Otto baseline period by one year to include CMIP5 simulations beginning in 1861 and end at 2009 due to lack of available and consistent forcing data. Our conclusions are robust to the choice of time period and to two other energy-budget calculation 
(c) 2015. All rights reserved.

methods (see Supplementary Information). As we use published radiative forcing series ${ }^{2,7}$ our analysis only determines the effect on calculated TCR due to changes in the $\Delta T$ term. The single largest contribution to the formal error in calculated TCR is, however, due to uncertainty in $\Delta F$. Otto used a Gaussian distribution with a $5-95 \%$ range of $\pm 0.58 \mathrm{~W} \mathrm{~m}^{-2}$. The IPCC $5^{\text {th }}$ Assessment Report reports a larger uncertainty range, so we use the Otto median with uncertainties based on Lewis \& Curry's more-sophisticated 2015 IPCC-based uncertainty distribution, which also accounts for non-Gaussian behaviour and cross correlation between terms (see Methods). This range requires scaling as it uses slightly different time periods but our result is not sensitive to this (see Supplementary Information). Although we focus on TCR, the equilibrium climate sensitivity (ECS) is another common metric:

$$
E C S=\frac{\Delta T}{\Delta F-\Delta Q} \Delta F_{2 \times C O_{2}}
$$

Where $\Delta$ Q is the system heat uptake which, being positive during warming, means that ECS is

larger than TCR. We do not calculate ECS here to avoid uncertainties associated with $\Delta Q$, and to avoid the assumption of linear climate response which is less accurate over the longer time periods required for equilibrium. ${ }^{17}$ However, as $\Delta T$ is in the numerators of Equations (1) and (3), any $\Delta T$ bias affects each calculation equally in percentage terms.

Formally, TCR refers to global near-surface air temperature ('tas' in CMIP5 nomenclature) for $\Delta T$ while observational temperature records have incomplete and varying geographical coverage and combine air temperatures over land and sea ice with near-surface water temperatures over oceans. These differences introduce biases as warming is not spatially uniform, sea ice coverage changes and 
(c) 2015. All rights reserved.

as air and water temperatures are expected to change differently. ${ }^{4,23}$ While some work accounted for these issues, it has not yet been included in energy-budget analyses. ${ }^{24}$

Here we use Equation (2) to calculate TCR in a consistent way from both observations and CMIP5 simulations. For observation-based TCR, $\Delta T$ is from HadCRUT4 and $\Delta F$ is the Otto median with IPCC-like uncertainty, which updated the CMIP5 mean based on observational constraints. For modelled TCR, $\Delta T$ is from the Cowtan et al. $(2015)^{4}$ CMIP5 series, $\Delta F$ is the CMIP5 forcing series for each model where available, and the multi-model mean otherwise ${ }^{7}$ (see Methods, Supplementary Information). Modelled data use the historical scenario from 1861-2005 and the Representative Concentration Pathway 8.5 (RCP8.5) from 2006. ${ }^{25}$ Scenario choice has little effect over the short period 2006-2009 used in the TCR calculation but may diverge from reality in the future.

Model temperatures are reconstructed in three ways: by using global air temperature ('tas-only'), by blending air temperature over land and sea ice with ocean temperatures over water ('blended') and by blending temperatures and using the historical geographical coverage of observations in HadCRUT4 ('blended-masked'). We assume that the modelled near-surface water temperature over oceans ('tos' in CMIP5 nomenclature) is equivalent to measured sea surface temperatures. Results are similar between models with different ocean layering: for example with 2.5 metre top-layer depth instead of 10 metres, suggesting tos is a robust measure of modelled sea surface temperature (see Supplementary Information).

The 'tas-only' reconstructions are used in standard model assessments of TCR, the 'blended' reconstructions represent the same reconstruction techniques as HadCRUT4 but with perfect data coverage and the 'blended-masked' reconstructions represent HadCRUT4.

Figure 1 shows the ensemble-median global temperature series for each reconstruction. Between 1861-1880 and $2000-2009$, HadCRUT4 warms slightly more $\left(0.75^{\circ} \mathrm{C}\right)$ than the multi-model median $\left(0.73^{\circ} \mathrm{C}\right)$ in a like-with-like comparison, although modelled tas-only series warmed more $\left(0.93^{\circ} \mathrm{C}\right)$. 
(c) 2015. All rights reserved.

This effect exceeds the approximately $10 \%$ difference quoted in Cowtan et al. (2015) ${ }^{4}$ which referred to the blending effect only, i.e. masking increases the effect further. Supplementary Table 8 shows that the masking bias is largely due to undersampling of rapidly warming polar regions. The blending and masking effects were not accounted for in the energy-budget studies cited here, although masking has been considered in some other analyses. ${ }^{26}$

After applying Equation (2), Figure 2 shows that the TCR from the blended-masked HadCRUT4 series of $1.34{ }^{\circ} \mathrm{C}$ falls at the $33^{\text {rd }}$ percentile of the blended-masked model distribution but at the $7^{\text {th }}$ percentile of TCR derived from tas-only model reconstructions.

Figure 3 shows that the energy-budget TCR inferred from tas-only temperature reconstructions is consistently higher than that inferred from blended or blended-masked reconstructions, and that both blending and masking contribute to the median bias of $24 \%$ in $\Delta T$. We correct for this bias by updating the blended-masked TCR derived from Equation (2) using Otto data for the best estimates of each parameter but a scaled Lewis \& Curry forcing distribution accounting for correlation between $\Delta F$ and $\Delta F_{2 \times C O_{2}}$ (see Methods). Our blended-masked estimate of 1.34 ${ }^{\circ} \mathrm{C}$ (range $0.8-2.6^{\circ} \mathrm{C}$ ) is updated by applying our derived correction of $24 \%$ (including $\pm 2 \%$ Gaussian uncertainty) to this distribution. The observation-based energy-budget calculation implies a best estimate for tas-only $\operatorname{TCR}$ of $1.66^{\circ} \mathrm{C}$ (range $1.0-3.3^{\circ} \mathrm{C}$, see Methods, Supplementary Information) consistent with the CMIP5 range. This result is robust to a variety of assumptions and correction approaches (see Supplementary Information). Intrinsic uncertainties in natural variability, model structure and real-world $\Delta F \quad$ are large and improved understanding of these factors may adjust these results in future. Of the $24 \%$ difference between tas-only TCR and the observation-based blended-masked estimate, we report that approximately 9 percentage points are due to blending and 15 percentage points to masking (from Supplementary Table 5). 
(c) 2015. All rights reserved.

Two further questions can be raised: is the difference in simulated warming rates between water and air realistic, and what does this mean for future research and impacts?

Modelled global air temperatures warm 7-9\% faster than blended air-water temperatures, with a component from the faster warming of air relative to water, and the remainder from changes in sea ice redistributing air and water measurements as discussed in Cowtan et al. (2015). We propose that changes in surface energy balance contribute to air temperatures warming faster: radiative equilibrium implies a temperature discontinuity at Earth's surface with surface temperatures higher than air, ${ }^{27}$ which drives vertical latent and sensible heat fluxes. The size of this discontinuity depends on atmospheric optical depth such that more $\mathrm{CO}_{2}$ and warming-induced increases in water vapour suppress the surface temperature discontinuity, meaning greater air temperature warming. Further adjustments in surface energy balance associated with non-radiative heat transfer affect the amplitude of this effect: warming increases evaporation at the surface while condensation increases at altitude. The increased latent heat transfer outweighs reductions in sensible heat fluxes in models ${ }^{28}$ and is related to the lapse-rate feedback which acts to reduce surface warming and increase warming of the air aloft.

The blending effect implies a limiting case of a $7-9 \%$ bias in model-observation comparisons for perfect geographical data coverage. Alternative measurements of surface and air temperatures over oceans are required to assess this expected bias in observations. The greatest immediate opportunities to reduce bias therefore appear to be in recovery efforts for historical data records ${ }^{29}$ and improved spatial interpolation ${ }^{11}$ which should reduce the potential $24 \%$ bias in observed global mean warming inferred over 1861-2009. Indeed, improved observational coverage has reduced the combined blending-masking bias to approximately $15 \%$ over the period 1970-2010 (see Supplementary Information). This implies that future estimates of TCR will be less sensitive to this bias as more data become available. 
(c) 2015. All rights reserved.

Other research that uses temperature changes over multidecadal or longer time scales may well be sensitive to the choice of temperature metric and researchers should be clear about which temperature metric or reconstruction method they are using to minimise the risk of biases introduced through inconsistent comparisons.

This issue also has considerable implications for policy discussions about limiting global average temperature to some particular level, such as $2{ }^{\circ} \mathrm{C}$ above pre-industrial. ${ }^{30}$ If our reported air-ocean warming differences are robust, then which global temperatures are relevant for policy? If it is decided that climate targets refer to global near-surface air temperature, then the current warming is likely $24 \%$ (range 9-40\%, see Supplementary Table 1) larger than reported by HadCRUT4. Previous energy-budget-based TCR estimates reported TCR values towards the lower end of the climate model range. These studies clearly highlighted their limitations, including issues of spatial coverage ${ }^{11}$ time sensitivity and the efficacy of different forcings. Nevertheless Otto stated:

"Our results match those of other observation-based studies and suggest that the TCRs of some of the models in the CMIP5 ensemble with the strongest climate response to increases in atmospheric $\mathrm{CO}_{2}$ levels may be inconsistent with recent observations"

However, in our like-with-like comparison, the Otto TCR best estimate of $1.3^{\circ} \mathrm{C}$ based on the HadCRUT4 blended-masked observational series falls at the $33^{\text {rd }}$ percentile of the CMIP5 blended-masked ensemble. There is therefore no evidence for significant disagreement between modelled and real-world TCR. This implies a TCR for global air temperature of $1.66^{\circ} \mathrm{C}\left(1.0-3.4^{\circ} \mathrm{C}\right)$, in better agreement with the CMIP5 multi-model mean of $1.8^{\circ} \mathrm{C}\left(1.2-2.4^{\circ} \mathrm{C}\right)$. We conclude that previous analyses that reported observation-based estimates toward the low end of the model range did so largely because of inconsistencies in the temperature reconstruction methods between models and observations. 
C) 2015. All rights reserved.

\section{Acknowledgements}

M.R. is funded by the Cloudsat and OCO-2 projects. The research described in this paper was performed at the Jet Propulsion Laboratory, California Institute of Technology, sponsored by NASA. E.H. is funded by the UK Natural Environment Research Council and the National Centre for Atmospheric Science. We thank Piers Forster for providing support regarding CMIP5 radiative forcing time series and Reto Knutti, Peter Jacobs and Peter Kalmus for substantial helpful comments. M.R. thanks Graeme Stephens for advisory support and helpful scientific discussions.

\section{Author Contributions}

M.R. performed the main analysis, produced the figures and drafted the article, K.C. provided code for temperature reconstruction methods and performed sensitivity tests, E.H. provided input on experimental design and helped write the article, M.S. provided input on experimental design, helped write the article and performed sensitivity tests.

\section{References}

1. Field, C., Barros, V., Mach, K. \& Mastrandrea, M. in ... II Contribution to the IPCC ... (Cambridge Uni. Press, 2014). at <https://www.ipcc.ch/pdf/assessment-report/ar5/wg2/WGIIAR5-FrontMatterA_FINAL.pdf>

2. Otto, A. et al. Energy budget constraints on climate response. Nat. Geosci. 6, 415-416 (2013).

3. Morice, C. P., Kennedy, J. J., Rayner, N. A. \& Jones, P. D. Quantifying uncertainties in global and regional temperature change using an ensemble of observational estimates: The HadCRUT4 data set. J. Geophys. Res. 117, D08101 (2012).

4. Cowtan, K. et al. Robust comparison of climate models with observations using blended land air and ocean sea surface temperatures. Geophys. Res. Lett. 42, 6526-6534 (2015).

5. Richter, I. \& Xie, S.-P. Muted precipitation increase in global warming simulations: A surface evaporation perspective. J. Geophys. Res. 113, D24118 (2008).

6. Taylor, K. E., Stouffer, R. J. \& Meehl, G. A. An Overview of CMIP5 and the Experiment Design. Bull. Am. Meteorol. Soc. 93, 485-498 (2012).

7. Forster, P. M. et al. Evaluating adjusted forcing and model spread for historical and future scenarios in the CMIP5 generation of climate models. J. Geophys. Res. Atmos. 118, 1139-1150 (2013).

8. Andrews, T., Gregory, J. M., Webb, M. J. \& Taylor, K. E. Forcing, feedbacks and climate 
C) 2015. All rights reserved.

sensitivity in CMIP5 coupled atmosphere-ocean climate models. Geophys. Res. Lett. 39, n/a-n/a (2012).

9. Bengtsson, L. \& Schwartz, S. E. Determination of a lower bound on Earth's climate sensitivity. Tellus B 65, (2013).

10. Lewis, N. \& Curry, J. A. The implications for climate sensitivity of AR5 forcing and heat uptake estimates. Clim. Dyn. 45, 1009-1023 (2015).

11. Cowtan, K. \& Way, R. G. Coverage bias in the HadCRUT4 temperature series and its impact on recent temperature trends. Q. J. R. Meteorol. Soc. 140, 1935-1944 (2014).

12. Hansen, J. Efficacy of climate forcings. J. Geophys. Res. 110, D18104 (2005).

13. Shindell, D. \& Faluvegi, G. Climate response to regional radiative forcing during the twentieth century. Nat. Geosci. 2, 294-300 (2009).

14. Shindell, D. et al. Spatial scales of climate response to inhomogeneous radiative forcing. J. Geophys. Res. 115, D19110 (2010).

15. Kummer, J. R. \& Dessler, A. E. The impact of forcing efficacy on the equilibrium climate sensitivity. Geophys. Res. Lett. 41, 3565-3568 (2014).

16. Marvel, K., Schmidt, G. A., Miller, R. L. \& Nazarenko, L. S. Implications for climate sensitivity from the response to individual forcings. Nat. Clim. Chang. (2015). doi:10.1038/nclimate2888

17. Knutti, R. \& Rugenstein, M. A. A. Feedbacks, climate sensitivity and the limits of linear models. Philos. Trans. R. Soc. A Math. Phys. Eng. Sci. 373, 20150146 (2015).

18. Huber, M., Beyerle, U. \& Knutti, R. Estimating climate sensitivity and future temperature in the presence of natural climate variability. Geophys. Res. Lett. 41, 2086-2092 (2014).

19. Schmidt, G. A., Shindell, D. T. \& Tsigaridis, K. Reconciling warming trends. Nat. Geosci. 7, 158-160 (2014).

20. Rose, B. E. J., Armour, K. C., Battisti, D. S., Feldl, N. \& Koll, D. D. B. The dependence of transient climate sensitivity and radiative feedbacks on the spatial pattern of ocean heat uptake.

Geophys. Res. Lett. 41, 1071-1078 (2014).

21. Winton, M., Takahashi, K. \& Held, I. M. Importance of Ocean Heat Uptake Efficacy to Transient Climate Change. J. Clim. 23, 2333-2344 (2010).

22. Armour, K. C., Bitz, C. M. \& Roe, G. H. Time-Varying Climate Sensitivity from Regional Feedbacks. J. Clim. 26, 4518-4534 (2013).

23. Ramanathan, V. The Role of Ocean-Atmosphere Interactions in the CO 2 Climate Problem. J. Atmos. Sci. 38, 918-930 (1981).

24. Santer, B. D. et al. Interpreting Differential Temperature Trends at the Surface and in the Lower Troposphere. Science (80-. ). 287, 1227-1232 (2000).

25. Riahi, K. et al. RCP 8.5-A scenario of comparatively high greenhouse gas emissions. Clim. Change 109, 33-57 (2011).

26. Jones, G. S., Stott, P. A. \& Christidis, N. Attribution of observed historical near-surface temperature variations to anthropogenic and natural causes using CMIP5 simulations. J. Geophys. Res. Atmos. 118, 4001-4024 (2013).

27. Goody, R. \& Yung, Y. L. in Atmospheric Radiation Theoretical Basics 388-425 (Oxford University Press, 1989). 
(c) 2015. All rights reserved.

28. DeAngelis, A. M., Qu, X., Zelinka, M. D. \& Hall, A. An observational radiative constraint on hydrologic cycle intensification. Nature 528, 249-253 (2015).

29. Thorne, P. W. et al. Guiding the Creation of A Comprehensive Surface Temperature Resource for Twenty-First-Century Climate Science. Bull. Am. Meteorol. Soc. 92, ES40-ES47 (2011).

30. United Nations Framework Convention on Climate Change: the Copenhagen Accord. FCCC/CP/2009/11/Add.1 (2009). 
(C) 2015. All rights reserved.
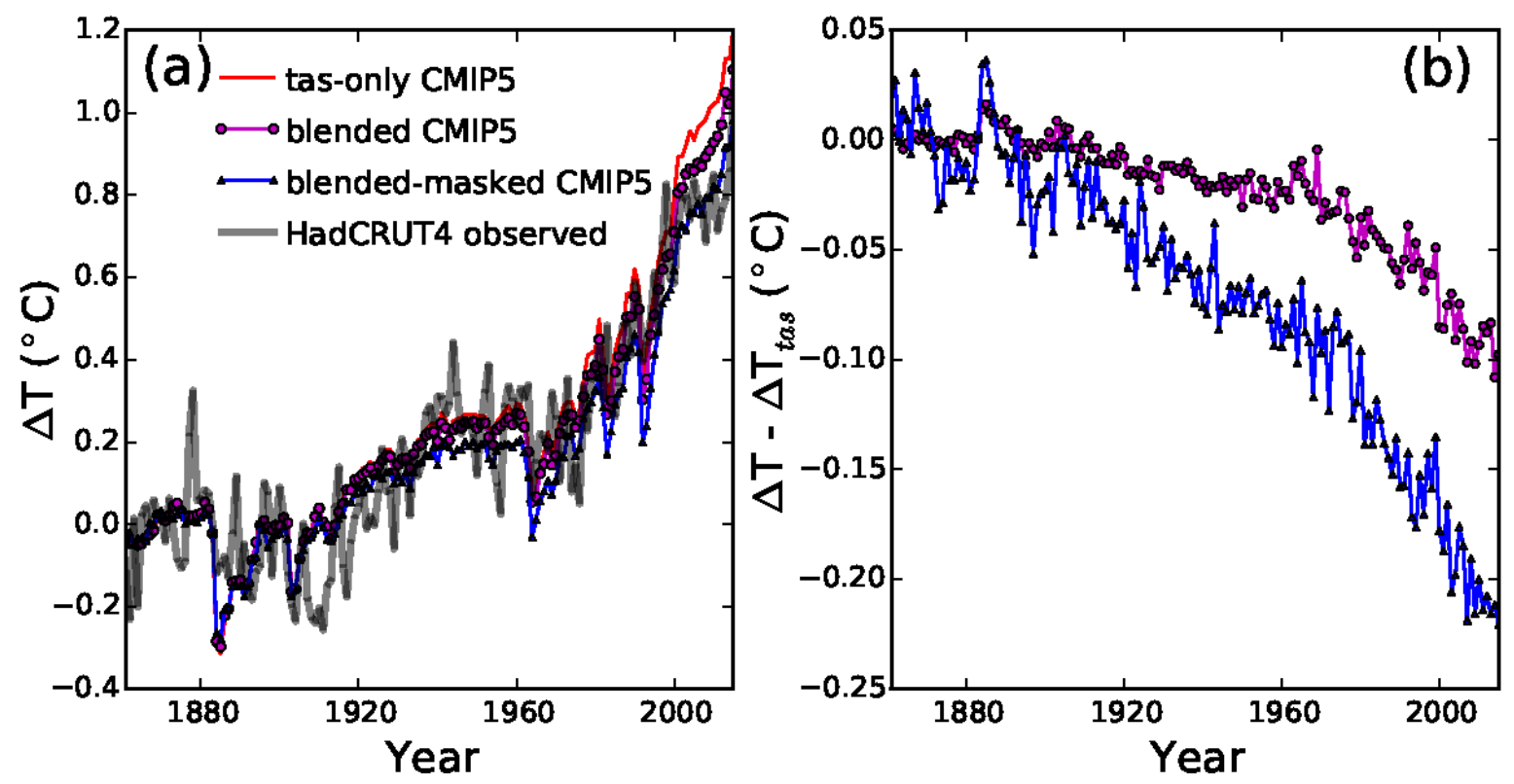

Figure 1 Median CMIP5-simulated temperature series by temperature reconstruction method compared with the HadCRUT4 observational series. (a): ensemble median temperature change relative to an 1861-1880 baseline for tas-only (red line), blended (magenta line with circles) and blended-masked simulations (blue line with triangles) along with HadCRUT4 blended-masked observations (thick grey line). (b): blended minus tas-only (magenta line with circles) and blended-masked minus tas-only (blue line with triangles). 
(C) 2015. All rights reserved.
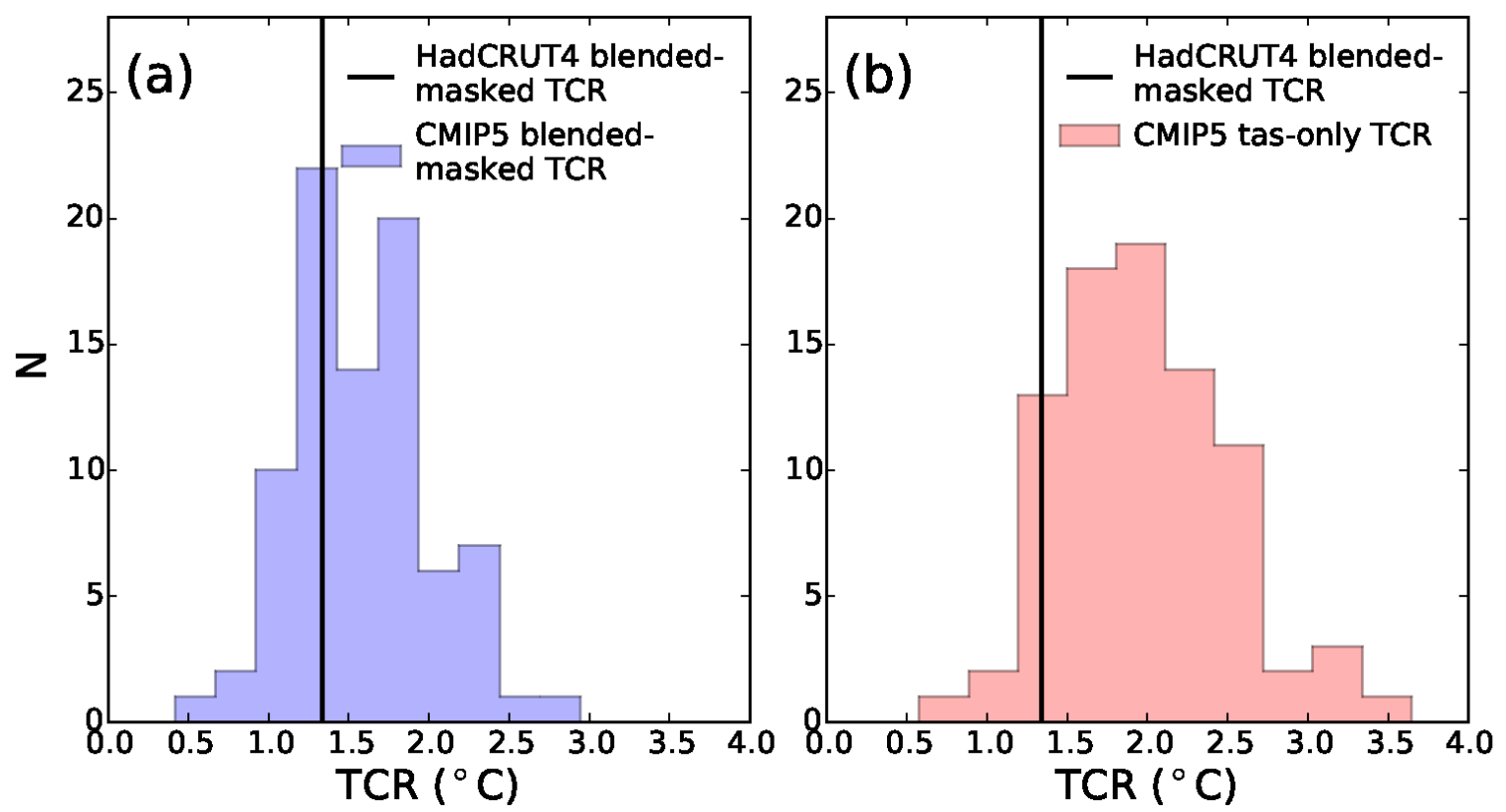

Figure 2 Histograms of transient climate response (TCR) calculated for CMIP5 simulations with the observation-based HadCRUT4-derived value also shown as a vertical line. HadCRUT4 used with Otto median forcing, CMIP5 simulations with model-specific forcing where available, multi-model mean otherwise. (a) consistent comparison between blended-masked observations and blended-masked CMIP5 simulations, where the observations fall at the $33^{\text {rd }}$ percentile of the model distribution (b) inconsistent comparison between blended-masked observations and global-air-temperature-derived values from CMIP5, where the observations fall at the $7^{\text {th }}$ percentile of the model distribution. 


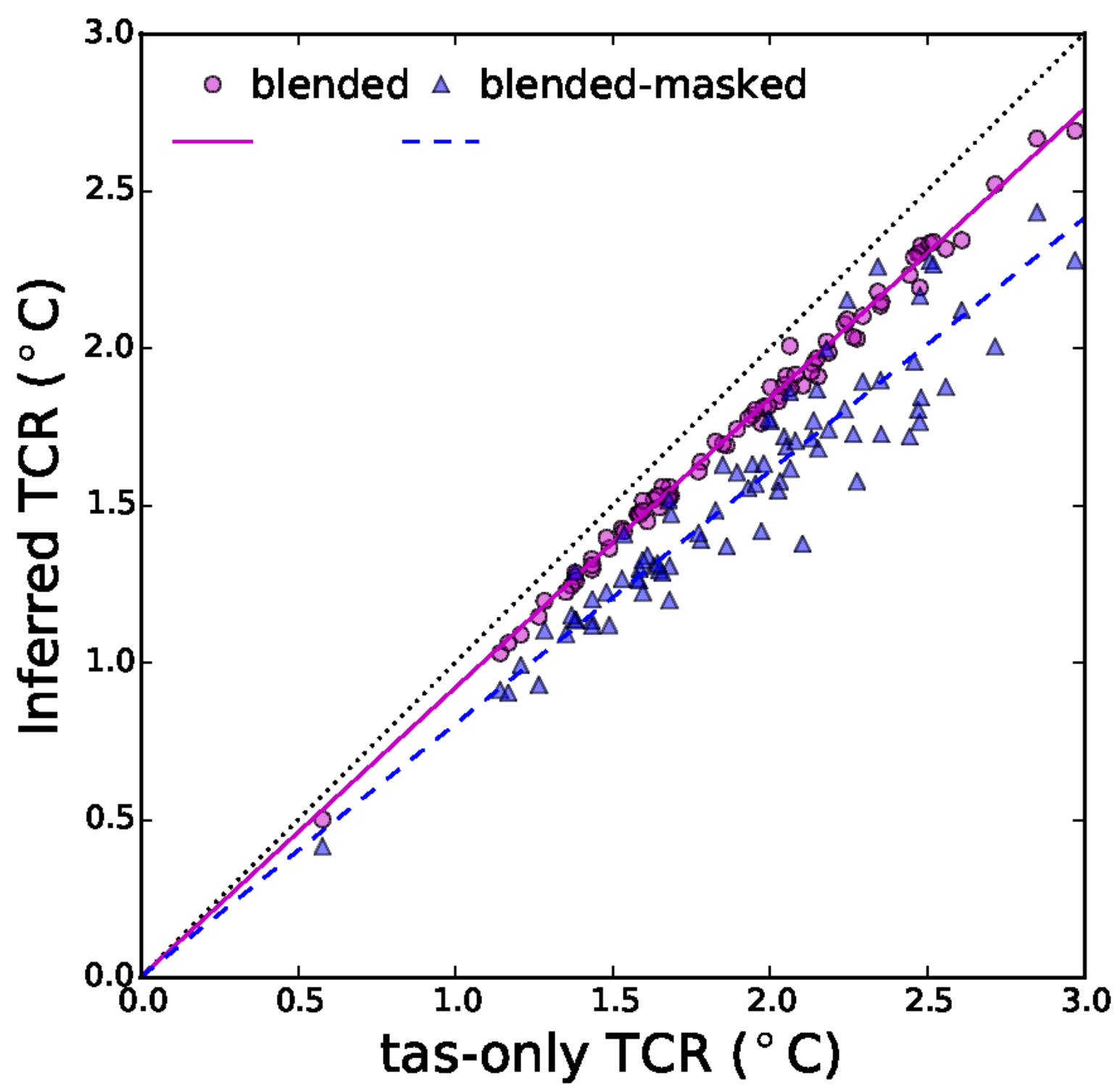

Figure 3 Energy budget estimates of transient climate response (TCR) using the Otto et al. energy-budget calculation applied to historical-RCP8.5 simulations. Values calculated from blended reconstructions (magenta circles) or blended-masked reconstructions (blue triangles) as a function of the tas-only derived TCR for each simulation. Best-fit lines shown for each case: solid magenta for blended and dashed blue for blended-masked, while the 1:1 line is shown as a dotted line. 


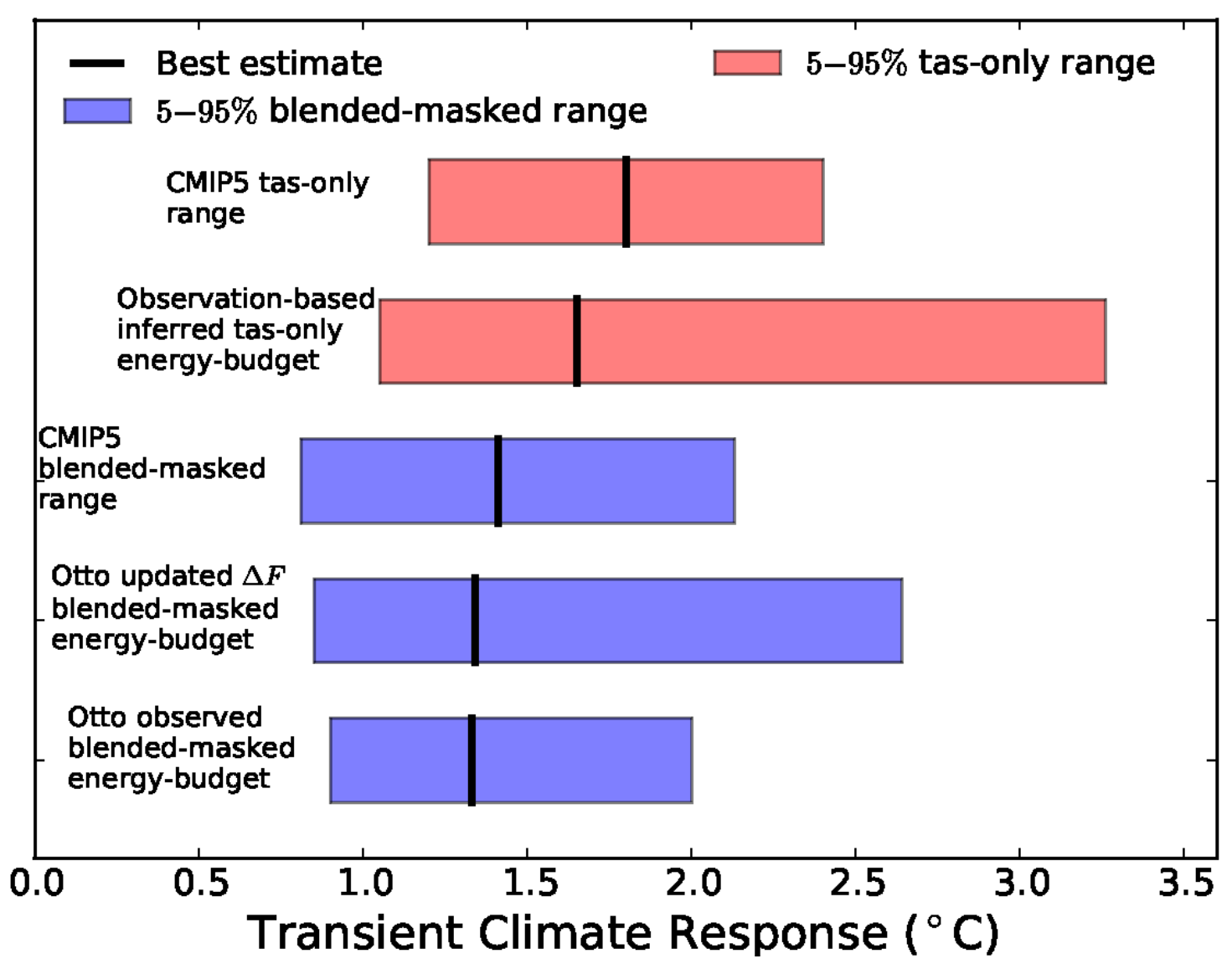

Figure 4 Comparison of modelled and observed TCR estimated from Earth's historical energy budget. The blue bars show blended-masked results, reported upwards as Otto et al.'s results using blended-masked HadCRUT4 observations, the same results using scaled Lewis \& Curry forcing, and the range when the same calculation is applied to blended-masked CMIP5 temperature series (one simulation per model). The red bars compare our bias-corrected estimates of tas-only TCR from HadCRUT4 using the Otto calculation with Lewis \& Curry forcings, and the canonical CMIP5 model range. The updated observation-based estimate is higher due to the corrected blending-masking bias, and has a wider range due to the greater uncertainty in radiative forcing series used. Boxes represents 5-95\% range and thick vertical lines are the best estimate. 
(C) 2015. All rights reserved.

\section{Methods}

The primary results require five main steps, with further analysis and sensitivity tests available in the Supplementary Information. The main steps are as follows:

1) Extraction of observed and modelled temperature series

2) Best estimates of radiative forcing time series for models and observations

3) Application of energy-budget calculation

4) Deriving a bias correction for the observation-based TCR calculation.

5) Applying the bias-correction to the blended-masked observation-based value in order to infer the tas-only TCR from observations.

\section{Temperature Series}

The observed HadCRUT4 temperature record was taken from

http://www.cru.uea.ac.uk/cru/data/temperature/HadCRUT4-gl.dat [downloaded 2016-03-22] while the CMIP5 temperature series were for the 84 CMIP5 historical-RCP8.5 simulations reported by Cowtan et al. (2015) with a small update to account for inconsistencies in how some models handled missing data and to include 2015 data. The code used for the present paper is available at http://www-users.york.ac.uk/ kdc3/papers/reconciled2016/ and the simulations used are listed in Supplementary Table 13 . The Otto et al. (2013) uncertainty of $\pm 0.20^{\circ} \mathrm{C}$ for changes from $1860-1879$ to $2000-2009$ is used, with $\Delta T$ assumed to follow a Gaussian distribution based on Otto's analysis of intrinsic measurement uncertainty combined with CMIP5-based estimates of internal variability.

For each simulation, 3 time series of temperature are calculated.

1) "tas-only" - the global mean average air temperature change.

2) "blended" - the global mean average temperature change using near-surface air temperatures ("tas") over land and sea ice, and near-surface ocean water temperatures ("tos") over ice-free ocean. These are referred to as "unmasked/anomaly/variable ice" in Cowtan et al. (2015). 
(c) 2015. All rights reserved.

3) "blended-masked" - similar to "blended" but calculated on a $5 \times 5$ degree with the historical month-by-month HadCRUT4 coverage mask applied. These are referred to as the "HadCRUT4 method" series in Cowtan et al. (2015).

Our blended-masked simulations are designed to match the HadCRUT4 methodology as closely as possible, using the same gridding and following the corresponding month-by-month HadCRUT4 data coverage. Global temperature anomaly is determined by taking the arithmetic mean of the Southernand Northern Hemisphere area-weighted means, as in HadCRUT4.

Each model's own sea ice field is used to determine whether to use air or water temperature measurements: in months where sea ice is present the air temperature is used, otherwise the water temperature is used. As discussed in Cowtan et al. (2015), this may lead to discontinuities as sea ice area changes. In CMIP5 sea ice retreat occurs mostly in summer, and summer air temperatures warm more quickly than ice-covered water temperatures which are strongly coupled to the freezing point of water and are insulated by the overlying sea ice. By the time sea ice melts, air temperatures have warmed by notably more relative to water temperatures since the reference period used in the anomaly calculation. The removal of ice therefore leads to an immediate jump downwards in reported temperature anomalies, as discussed in Cowtan et al. (2015). The use of "tos" is taken as the closest equivalent to observational SST records which sample near-surface water temperatures. Each individual CMIP5 simulation is then baselined such that the 1861-1880 mean temperature anomaly is zero, and the CMIP5 median then comes from the median temperature of the ensemble in each year.

The comparison in temperature changes shown in Figure 1 is based on the difference between the tas-only, blended and blended-masked simulations. The $24 \%$ difference we report for $\Delta T$ refers to the median of the set of model tas-only divided by blended-masked $\Delta T$ values. The difference 
(c) 2015. All rights reserved.

seen in Figure 1 is slightly higher as Figure 1 shows the difference of the medians rather than the median of the differences.

\section{Radiative Forcing}

Radiative forcing used with HadCRUT4 to obtain the "observation-based" TCR was taken from Otto et al. (2013). This series is largely diagnosed from models but was updated based on some observation-based constraints so we take it as the best understanding of real-world historical

$\Delta F$. It uses a version of the CMIP5 multi-model-mean historical-RCP4.5 forcing with updates to better match observed natural variability and with an upward adjustment of $0.3 \mathrm{~W} \mathrm{~m}^{-2}$ based on evidence for weaker real-world cooling by tropospheric aerosol than that simulated by the CMIP5 simulations. The weaker cooling effect of aerosols leads to an increase in the total forcing and therefore a lower calculated value of TCR as $\Delta F$ is in the denominator of Equation (1). For the CMIP5 simulation $\Delta F \quad$ we used the historical-RCP8.5 simulated forcing series from http://www.see.leeds.ac.uk/research/icas/research-themes/climate-change-and-impacts/physical-cli mate-change/current-research/ipcc-intergovernmental-panel-on-climate-change-reports-and-forcing s/ [last accessed 2016-03-25]. We use all models which provide a full radiative forcing time series from 1861 onwards. Each model uses its own forcing if available $(\mathrm{N}=54)$, or the multi-model mean otherwise $(\mathrm{N}=30)$. Supplementary Information shows that the TCR best estimate is not sensitive to this choice.

There is substantial uncertainty in $\Delta F$ and various values have been calculated for observational series. Otto et al. (2013) reported $1.95 \pm 0.58 \mathrm{~W} \mathrm{~m}^{-2}$ for the change from $1860-1879$ to $2000-2009$, while Lewis \& Curry (2014) reported $1.98 \mathrm{~W} \mathrm{~m}^{-2}\left(0.99-2.86 \mathrm{~W} \mathrm{~m}^{-2}\right)$ for the change from 1859-1882 to $1995-2011$. The Otto results represents the 5-95 \% range of a Gaussian distribution, while Lewis \& Curry used updated forcing estimates from the IPCC $5^{\text {th }}$ Assessment Report, accounting for 
(c) 2015. All rights reserved.

individual forcings and allowing for non-Gaussian distributions in some components. We build on the Lewis \& Curry forcing uncertainty as it more accurately represents the IPCC's best understanding and includes a more sophisticated treatment of the cross correlations between terms.

To produce $\Delta F$ and $\Delta F_{2 \times \mathrm{CO}_{2}}$ distributions we use the Lewis \& Curry (2014) code that is available at https://niclewis.wordpress.com/the-implications-for-climate-sensitivity-of-ar5-forcing-and-heat-upta ke-estimates/ [last accessed 2016-04-30]. We extract 1 million samples from each of the output distributions. These distributions include some correlation due to the correlated uncertainty in the $\mathrm{CO}_{2}$ component that is present in each.

The Lewis \& Curry $\Delta F \quad$ values are then scaled such that their medians match those from Otto data for $1861-1880$ to $2000-2009$, resulting in a distribution with the same shape as that derived in Lewis \& Curry, a median of $1.94 \mathrm{~W} \mathrm{~m}^{-2}$ and $5-95 \%$ range of $0.97-2.81 \mathrm{~W} \mathrm{~m}^{-2}$. This scaling is required to ensure that the best estimate matches the period used.

The $\Delta F_{2 \times \mathrm{CO}_{2}}$ distribution is then scaled such that it has a median of $3.44 \mathrm{~W} \mathrm{~m}^{-2}$ and a range of $\pm 10 \%$, consistent with Otto's values, but maintaining the correlation with the $\Delta F$ term as in Lewis \& Curry.

\section{Energy-budget calculation to obtain TCR}

Temperature and radiative forcing differences were calculated using Equation (2) by taking the mean values for $\Delta T$ and $\Delta F$ from 2000-2009 and subtracting the means from 1861-1880. The mean forcing at $\mathrm{CO}_{2}$ doubling was taken to be $3.44 \mathrm{~W} \mathrm{~m}^{-2}$, from Forster et al. (2013). In addition, different time periods and the one-box calculation of Held et al. (2010) and the trend method of 
(c) 2015. All rights reserved.

Bengtsson \& Schwartz (2013) were also assessed in the Supplementary Information and our results are found to be generally robust to the choice of method.

For the HadCRUT4-based estimate, the distributions of $\Delta F_{2 \times \mathrm{CO}_{2}}, \Delta T$ and $\Delta F$ were sampled $1,000,000$ times to obtain the TCR distribution. Our best estimate is $1.34^{\circ} \mathrm{C}$ versus $1.32{ }^{\circ} \mathrm{C}$ in Otto due to the 1-year shift in the baseline period from $1860-1879$ to $1861-1880$, and possibly differences between HadCRUT4 versions and the skewed forcing distribution. Due to the broader forcing uncertainty, the range in our TCR is $0.8-2.6^{\circ} \mathrm{C}$ (see Supplementary Table 12).

For Figures 2 and 3 the best estimates of TCR according to the energy-budget calculation Equation (1) are shown using each simulation's temperature reconstructions (tas-only, blended and

blended-masked) to calculate $\Delta T$ with the model-specific $\Delta F \quad$ if available, and the multi-model mean $\Delta F \quad$ otherwise. For the model TCRs used in Figure 4, we use the first simulation of each model in the ensemble.

\section{Resultant TCR bias correction}

Energy-budget calculations performed on blended-masked simulations were found to consistently underestimate the tas-only value and so a correction was determined by performing a linear regression of CMIP5 tas-only TCR against blended-masked TCR for the 84 available historical-CMIP5 simulations. This linear regression was constrained to go through zero and found to have a gradient of $1.24 \pm 0.02$ ( $5-95 \%$ error, as throughout). To this precision, the same result is determined when using the 54 simulations for which model forcing is available.

This result suggests that an upward revision of $24 \%$ is required to accurately represent tas-only TCR given the result of a calculation using blended-masked temperature series. This $24 \%$ value is appropriate for the time period used, and is found to change with time (see Supplementary 
(c) 2015. All rights reserved.

Information) - it was larger historically and is now tending towards approximately $15 \%$ for HadCRUT4 coverage over 1970-2010 or 7-9\% for perfect coverage (i.e. blending bias only).

\section{Applying TCR bias correction}

Having obtained an adjustment factor, $\alpha$, of $1.24 \pm 0.02$ from linear regression, we can apply it to the blended-masked energy-budget TCR in order to estimate the relevant tas-only TCR from:

$$
T C R_{\text {tas-only }}=\alpha \Delta F_{2 \times C O_{2}} \frac{\Delta T_{\text {blended }- \text { masked }}}{\Delta F}
$$

We use the distributions described above with the HadCRUT4-based $\Delta T$ and broader $\Delta F$

range with $\alpha$ taken to be a Gaussian with the mean and error determined from the linear regression fit. Each of these distributions is sampled 1,000,000 times to derive a 1,000,000-member set of $T C R_{\text {tas-only }}$ values from which the median and range statistics are extracted. Our blended-masked TCR of $1.34{ }^{\circ} \mathrm{C}\left(0.8-2.6^{\circ} \mathrm{C}\right.$ ) becomes $1.66^{\circ} \mathrm{C}$ (range $1.0-3.3^{\circ} \mathrm{C}$, see Supplementary Table 12 ).

Alternatively $\alpha$ could be sampled from the distribution of $\mathrm{N}=84$ ratios of tas-only TCR to blended-masked TCR determined previously. Supplementary Table 13 shows that this would result in $1.67^{\circ} \mathrm{C}$ (range $1.0-3.3^{\circ} \mathrm{C}$ ). 